\title{
Resilience and Higher Education Support as Protective Factors for Student Academic Stress and Depression During Covid-19 in the Netherlands
}

\author{
Melissa Versteeg and Rutger Kappe* \\ Department of Student Success, InHolland University of Applied Sciences, Haarlem, Netherlands
}

Background: The corona pandemic has forced higher education (HE) institutes to transition to online learning, with subsequent implications for student wellbeing.

Aims: This study explored influences on student wellbeing throughout the first wave of the corona crisis in the Netherlands by testing serial mediation models of the relationships between perceived academic stress, depression, resilience, and HE support.

OPEN ACCESS

Edited by:

Haibo Yang,

Tianjin Normal University, China

Reviewed by:

Santosh Kumar Swain,

Siksha 'O' Anusandhan

University, India

John W. Yuen,

Hong Kong Polytechnic University,

Hong Kong, SAR China

${ }^{*}$ Correspondence: Rutger Kappe

rutger.kappe@inholland.n!

Specialty section:

This article was submitted to

Public Mental Health,

a section of the journal

Frontiers in Public Health

Received: 06 July 2021 Accepted: 22 September 2021

Published: 21 October 2021

Citation:

Versteeg M and Kappe R (2021) Resilience and Higher Education Support as Protective Factors for

Student Academic Stress and Depression During Covid-19 in the

Netherlands.

Front. Public Health 9:737223.

doi: 10.3389/fpubh.2021.737223
Methods: The Covid-19 International Student Wellbeing Study (C19 ISWS) was used, with a total sample of 2,480 higher education students studying at InHolland Universities of Applied Sciences in the Netherlands. Student subgroups were created, so that students with low and high perceived academic stress could be assessed, in addition to depressed and non-depressed students. Predictive model fit was tested using Macro PROCESS.

Results: A significant serial mediation model for the total student sample was revealed, including protective mediating effects of resilience and HE support on the positive direct effect of perceived academic stress on depression. At subgroup level, significant (partial) predictive effects of resilience on depression scores were noted. A partial serial effect between resilience and HE support was found for students with low perceived stress levels, whereas a parallel partial mediation model was present among highly academically stressed students. Regarding non-depressed students, a full parallel mediation model was found, whereas the model for depressed students inadequately explained the data.

Conclusions: Overall, resilience and HE support mediate the predictive effect of academic stress on depressive symptoms among students. In addition, substantial differences in model fit arise when inspecting the students on a subgroup level. These findings contribute to the gap in knowledge regarding student wellbeing during the Covid-19 pandemic in the Netherlands, in addition to providing novel insights on student subgroup dynamics. While Covid-19 restrictions continue to demand online learning, student wellbeing may be enhanced overall by targeting resilience and increasing awareness and availability of HE support services. The current study also highlights the need for differential approaches when examining wellbeing for specific student groups.

Keywords: academic stress, Covid-19, depression, higher education, resilience, wellbeing, students, support 


\section{INTRODUCTION}

Higher education (HE) students face profound lifestyle changes. Moving away from home, changes in peer support, an increase in decisions regarding personal and professional Opportunities, and elevated levels of stress from relationships can interfere with wellbeing (1-5). During student life, over half of enrolled students experience emotional problems (3) which may result from academic overload, pressure to succeed, peer competition, and less time to spend on leisure or family (6). When students experience psychological distress, academic productivity drops (7). Students who are experiencing depression or other psychological problems are generally found to have trouble maintaining progress, and encounter difficulty adjusting to higher education (3). Academic failure rises with increased psychological problems in students and many students report psychosocial issues prior to dropping out $(7,8)$.

For 2019 and 2020, Dutch populations aged 18 to 25, reported the highest levels of unhappiness compared to other age groups, in addition to reporting the highest levels of dissatisfaction regarding the state of their mental health (9). In the Netherlands, major depression has been identified as the most common individual mental health disorder (10). Global analyses indicate that psychological disorders will have presented by age 24 in $75 \%$ of cases (11). With major depressive disorders, occurrence during earlier life stages increases recurrence rates during early adulthood by $400 \%$ (12). With an average age at higher educational graduation of 23.4 years for students in the Netherlands (13), a substantial group will experience psychological problems during student life. The bulk of such problems are predicted to occur among younger students and estimates suggest the prevalence of psychological problems to be over $30 \%$ among student populations $(3,7,14)$.

Besides psychological problems such as depression, stress is also reported to play a major role in student wellbeing (1517). Greater perceived academic stress, including increases in perceived academic workload, and higher levels of loneliness within the academic context, reveal a stronger effect on depression than do indicators of cumulative academic demands or academic grades (18). In the Netherlands, an increasingly demanding student life has been reported. Performance pressure, finances, and rigid study continuation criteria are noted as important academic contributors to stress among Dutch students (7). Moreover, students' stress appraisal directly impacts development of psychological problems. For those who feel that stress is negative, and perceive it as involving serious consequences or threat, frequent stress exposure is linked to higher levels of psychological distress and use of support services $(16,19,20)$.

To help students effectively cope with stress and mental health issues, support resources are required $(21,22)$, and studies indicate a potential role for the HE institutes in providing these resources (23-25). In the presence of adequate support, the effect of stress on development of psychological problems is reduced and may even be fully remedied (26). However, for younger people, experiencing psychological distress is often accompanied by perceived stigma, feelings of embarrassment, and a preference for self-reliance, which hamper formal helpseeking behaviours (24). In addition, students with depression or anxiety who fail to seek support frequently report unawareness of available services (27). Students with higher levels of distress are less able to effectively seek help. This highlights the possibility for educational institutes to increase education, awareness, and availability of wellbeing promoting facilities, including online resources $(24,25)$.

Student wellbeing during the coronavirus (Covid-19) outbreak is heavily impacted, with students reporting higher levels of hardship and vulnerability during this global health crisis. Students, as compared to other population groups, experience added duress due to the educational transition to a predominantly online environment $(5,28-30)$, and report significant stress caused by changes in teaching methods (31). Grappling with the transition to remote learning presents challenges to students, with the effects of the pandemic described as removing "both the opportunity and the will to be productive" (32). Government-imposed restrictions require social distancing and isolation, with subsequent increases in psychological distress and development of disorders including stress, depression, irritability, and insomnia (33). These emerging threats are inciting higher educational institutes to prioritise questions concerning their duty of care for student wellbeing (34), which motivated investigation of HE support facilities in the current study.

Trends of elevated psychological susceptibility during Covid19 are found globally among student populations, including students in China, Italy, England, Greece, the United States, Germany, and France $(5,28,35-42)$, but have yet to be studied in the Netherlands. The observed declines in wellbeing are attributed to online learning, isolation from peers, strained relationships with teachers and classmates, and relocation following school campus closure $(5,43)$. A recent meta-analysis estimated the overall prevalence of depression among students to range from 32.9 to $49.1 \%$ (44).

The first recorded case of the coronavirus in the Netherlands occurred during early 2020. Following its rapid spread, the government announced restrictions with stringency increases as the Covid-19 virus spread (Table A1). Among these restrictions, a call to stop teaching at location was announced. An expansion of government-imposed restrictions continued until May 2020, after which a first tentative step towards limited reopening was introduced, as the first wave of infections receded $(45,46)$.

Examining students' perspectives on how educational institutes may enhance wellbeing reveals relevant themes for HE student services and support facilities during the Covid-19 restrictions. From students' standpoint, increasing awareness of services, promoting their use, and improving availability, range, and quality of support services is instrumental to increased wellbeing (23). With current restrictions demanding an expansion of online facilities, $\mathrm{HE}$ services may seek to expand online support facilities. Reviews of web-based and computer-delivered interventions describe benefits to student mental health, with around 50\% demonstrating at least one significant positive outcome following online interventions (47-49). 
Resilience is also a much-favoured way to promote student wellbeing, through its positive impact on one's capacity to effectively navigate stressful environments (1). Resilience, defined as the ability to bounce back following stress exposure (50), is portrayed as a vital component to adaptive recovery, and refers to stabilisation following threats to wellbeing (51). In a metaanalysis, it was shown that resilience is positively correlated with indicators of mental health (52). More so, the positive relationship between resilience and mental health is strongest following exposure to significant adversity. Thus, to effectively activate resilience, stress exposure is required (52-54).

Resilience is pivotal to maintaining balance on individual and societal levels and is especially relevant during the Covid19 pandemic (55). Covid-19 studies on wellbeing emphasise resilience as mediating the negative outcomes related to Covid19 stress and fears $(56,57)$. According to the challenge model of resilience (58), an optimal range of stress exposure exists within which individuals can cultivate resilient response. Stress levels that are too low activate sub-optimal resilient responses, and stress levels that are too high predict negative outcomes as stress exposure becomes overwhelming. In addition, strong ties exist between resilience and support, where support promotes resilient recovery following stress exposure, in addition to improving help-seeking attitudes and increasing one's capacity to identify and utilise supportive resources $(24,59,60)$.

With evident roles for academic stress, resilience, and support on student wellbeing, the current study proposes an explanatory model to explain the relationships between Covid-19 related academic stress, depression, resilience, and HE support for students studying at HE institutes throughout the Netherlands during the coronavirus pandemic. The Dutch HE system involves two distinct forms of higher education. The first regards academic research oriented higher education, offered by universities (in Dutch: wetenschappelijk onderwijs). The second form includes higher professional education offered by universities of applied science (in Dutch: hoger beroepsonderwijs). The current study included higher professional education students to ensure sample homogeneity.

The hypothesised model of academic stress on depression during Covid-19 used in the current study includes a direct predictive effect of academic stress perception on reported levels of depression, in addition to proposing three predictive indirect effects: (1) a partial mediation effect of resilience, where higher resilience has a stronger protective effect on depression, (2) a partial mediation effect of HE support, where students who report higher identification of support facilities available within the HE context are believed to also experience a stronger protective effect on depression rating, and (3) a partial serial mediation effect where the indirect effect of resilience and $\mathrm{HE}$ support in succession offers a protective effect on depression in HE students (see Figure 1).

Previous studies indicate a need to focus on differential effects between student subgroups to address gaps in available knowledge $(7,18,57)$. As such, the current study included model fit tests for student subgroups. Predictive model fit examinations were carried out for all eligible HE students studying in the Netherlands, and model fit was subsequently analysed for four

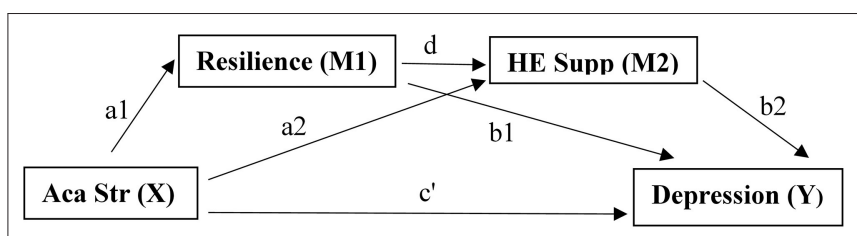

FIGURE 1 | Explanatory serial mediation model with hypothesised direct pathway, independent mediation pathways, and serial mediation pathway between academic stress, depression, resilience, and HE support. Aca Str, academic stress; HE Supp, higher education support.

students subgroups: (1) HE students who report low perceived academic stress during the Covid-19 pandemic, (2) HE students who report high perceived academic stress during the Covid-19 pandemic, (3) HE students whose reported levels of depression approaching clinical diagnoses of depression (61), and (4) $\mathrm{HE}$ students whose depressive symptom profiles are below the threshold for clinical depression. Based on available literature $(57,58)$, we expect that higher levels of stress decrease the protective mechanisms provided by resilience and the ability to identify HE support. In addition, we expect that students reporting depressive levels linked to clinical depression will experience a lower protective effect of resilience and HE support. The current study thus provides a novel model analysis of student wellbeing throughout the Covid-19 pandemic in the Netherlands, and additionally includes novel examinations of wellbeing among student subgroups.

\section{METHOD}

\section{Survey}

Across 26 countries and 110 higher educational institutes, students were invited to complete the Covid-19 International Student Well-being Study (C19 ISWS). Invitations were sent via email, where participating research groups received a countryspecific, or institute-specific link for survey distribution. This approach limited survey distribution and subsequent data collection to respondents studying in the Netherlands (29). The survey was completed online via Qualtrics survey tool in accordance with European guidelines on General Data Protection Regulation (GDPR). The study was approved on ethical standards as defined by the Ethics Committee for Social Sciences and Humanities at the University of Antwerp, in addition to meeting standards set by the institutional review board at the InHolland University of Applied Sciences.

The C19 ISWS includes seven domains: (1) sociodemographic information, such as age, gender, and migration status, (2) study-related information such as study field, HE institute, and perceived importance of study, (3) changes due to the Covid-19 outbreak, including financial resources, living conditions, lifestyle, and activity levels, (4) Covid-19 infections, symptoms, and concerns like comorbidity, stigma, and risk perception, (5) stressors, informal support, and mental wellbeing, (6) student-specific questions and concerns such as help-seeking behaviours, perceived stress, and satisfaction 
with the HE communication strategies, and (7) Covid-19 knowledge and information, including questions on the students' attitudes towards government-imposed restrictions and communication strategies. The C19 ISWS questionnaire is available elsewhere (62).

The C19 ISWS was designed to measure a broad range of theme's including several widely implemented scales to collect data on wellbeing just prior to, or after, the initial peak in Covid19 infections. In the Netherlands, participants of the C19 ISWS completed the survey between May 6th 2020 and May 18th 2020. The Dutch government reduced some of the lockdown restrictions following several weeks of an "Intelligent Lockdown" phase on May 11th, 2020, which included a reopening of middle schools, but this ease of restrictions included no changes relevant to teaching methods at HE institutes (see Table A1).

\section{Participants}

All study participants were HE students, actively enrolled in a study programme at InHolland Universities of Applied Sciences throughout the Netherlands. Participation was voluntary and participants were invited to partake in the study if they were currently enrolled and were aged 17 years or older. Participants were required to give consent prior to proceeding. Of the participants who partook in the study, those who had successfully completed the survey were included in the dataset.

The cohort of students included 2,835 participants. Data homogeneity inspection revealed that enrolment status created a significant impact on the distribution of the dependent variable; $F(3,2,821)=15.760, p<0.001$. Post-hoc contrasts indicated that the effect of fulltime enrolment was significantly different from other forms of enrolment. Furthermore, students who identified as gender " $\mathrm{x}$ " included 10 individuals who scored significantly higher on dependent variable [mean $(M)=2.675$, standard deviation $(\mathrm{SD})=0.753$ ] than students who identified as male $(\mathrm{M}=2.193, \mathrm{SD}=0.630)$ or female $(\mathrm{M}=2.273, \mathrm{SD}=0.611)$ $(t(827)=-2.399, p=0.009 ; t(2,104)=-2.071, p=0.019)$. As previous examination of the CES-D8 has not validated reliable use for this gender group (63), gender " $\mathrm{x}$ " was excluded from the final dataset. Subsequently, fulltime HE enrollers, and those identifying as male or female were included in the final dataset.

The final sample used for analysis included 2,480 students with fulltime, 4 year HE enrolment of mean age 21.78 years $(\mathrm{SD}=3.155)$. Of the respondents 775 were male $(30.4 \%)$ and the remaining 1,725 were female $(69.6 \%)$. The study sample is described in further detail in Table 1.

\section{Measurements \\ Depression}

The level of depressive symptoms was measured with the Centre for Epidemiological Studies-Depression scale (CES-D8) short version, which was integrated in the C19 ISWS and has been tested as a reliable and valid tool to measure depressive symptoms in men and women $(63,64)$. This 8 -item questionnaire asks respondents to indicate to which degree they agree with statements that reflect on thoughts, feelings, emotions, and energy levels over the past week. Responses are given according to a 4-point Likert scale, where 1 indicates "none or almost none
TABLE 1 | Sociodemographic characteristics of participants $(N=2,480)$.

\begin{tabular}{|c|c|c|}
\hline & $N$ & $\%$ \\
\hline \multicolumn{3}{|l|}{ AGE IN YEARS } \\
\hline$<18$ & 260 & 10.5 \\
\hline $18-20$ & 678 & 27.3 \\
\hline $21-23$ & 995 & 40.1 \\
\hline $24-27$ & 426 & 17.2 \\
\hline$>28$ & 121 & 4.9 \\
\hline \multicolumn{3}{|l|}{ GENDER } \\
\hline Male & 755 & 30.4 \\
\hline Female & 1,725 & 69.6 \\
\hline \multicolumn{3}{|l|}{ STUDY YEAR } \\
\hline First & 739 & 29.8 \\
\hline Second & 594 & 24.0 \\
\hline Third & 497 & 20.0 \\
\hline Fourth & 453 & 18.3 \\
\hline Fifth or more & 197 & 7.9 \\
\hline \multicolumn{3}{|l|}{ MIGRATION STATUS } \\
\hline Born inside the Netherlands & 2,219 & 89.5 \\
\hline Born outside the Netherlands & 261 & 10.5 \\
\hline \multicolumn{3}{|l|}{ PARENTAL EDUCATION } \\
\hline \multicolumn{3}{|l|}{ Father } \\
\hline Less than secondary & 132 & 5.3 \\
\hline Secondary & 1,115 & 45.0 \\
\hline Higher education & 1,044 & 42.1 \\
\hline Unknown & 189 & 7.6 \\
\hline \multicolumn{3}{|l|}{ Mother } \\
\hline Less than secondary & 111 & 4.5 \\
\hline Secondary & 1,276 & 51.5 \\
\hline Higher education & 957 & 38.6 \\
\hline Unknown & 136 & 5.5 \\
\hline \multicolumn{3}{|c|}{ HIGHER EDUCATION GENERATION } \\
\hline First generation & 1,075 & 43.3 \\
\hline Other & 1,405 & 56.7 \\
\hline
\end{tabular}

of the time", 2 indicates "some of the time", 3 indicates "most of the time", and 4 indicates "all or almost all of the time". The items ask an estimation of "how much of the time during the last week..." followed by specific item content, such as "you felt everything was an effort", "your sleep was restless", or "you felt sad". The total scores are averaged, with higher scores indicating a higher presence of depressive symptoms, and a summed mean of 3.0 or higher indicating depression $(61,65,66)$. Cronbach's alpha for the CES-D8 in the sample was 0.860 . The sample had an average CES-D8 score of 2.280 , with a standard deviation of 0.619 . When grouped into a depressed and non-depressed subset according to scoring procedures, $16.3 \%$ reported symptom levels in accordance with clinical depression $(61)(N=404)$.

\section{Academic Stress}

Covid-19 related academic stress was measured using a 4item scale included in the C19 ISWS domain on studentspecific questions and concerns within the specific context of the 
coronavirus pandemic. All four items enquired about perception of changes in academic stress following the coronavirus pandemic and changes in students' academic experiences. Factor analyses conducted by the C19 ISWS consortium revealed four items which adequately assessed perceived academic stress during the transition to online teaching (29). This short assessment included evaluation of academic workload, course expectations, completion of the academic year, and teaching methods (63). Corresponding items included statements such as "my university/college workload has significantly increased since the Covid-19 outbreak" and "I am concerned that I will not be able to successfully complete the academic year due to the Covid-19 outbreak". Responses were required along a 5point Likert scale were 1 indicated "total agreement", 3 indicated a "neutral" response, and 5 indicated "total disagreement" with the statement. All four item scores had to be reversed to allow intuitive interpretation, and a summed mean score was calculated. As such, a higher mean score indicates higher perceived academic stress following the Covid-19 restrictions and the HE transition to online teaching, with total scores ranging from 4.00 to 20.00 , and summed mean scores between 1.00 and 5.00. A reliability analysis on the current dataset resulted in a Cronbach's alpha of 0.730 . The respondents scored an average of 3.371 on the summed mean academic stress scale, with a standard deviation of 0.854 .

In addition, academic stress scale total scores (range 4.0020.00) were transformed to subset two groups; those who experienced low levels of academic stress, and those who experienced high levels of academic stress. The average total score on the academic stress scale for the sample was $14.86(\mathrm{SD}=3.41)$. Cut-off scores were based on the total scores to allow clean cutoff lines inherent to the use of Likert-scale responses. As such, students scoring between the minimum +1 SD (4.00-7.41) were assigned to the low academic stress group, and the maximum score - 1 SD (16.59-20.00) was used to identify the high academic stress group. In practise, as the academic stress scale is based on a 5-point Likert response scale, the low academic stress group scored between 4.00 and $7.00(N=63, \mathrm{M}=1.480, \mathrm{SD}=0.289)$ whereas the high academic stress group scored between 17.00 and $20.00(N=839, \mathrm{M}=4.611, \mathrm{SD}=0.282)$. Following group allocation, the summed mean scores of the academic stress scale were used for subsequent analyses.

\section{Resilience}

Resilience was measured using the Brief Resilience Scale (BRS) which is a short, self-reported 6-item measure of resilience with proven validity and reliability in other cohort studies (50). This scale was included in the C19 ISWS within the country-specific module. An indication of agreement with the statements was required according to a 5-point Likert scale. 1 indicated "total disagreement", 3 indicated a neutral response, and 5 indicated "total agreement" with the provided statements. BRS items included "I tend to bounce back quickly after hard times", "I have a hard time making it through stressful events", and "it does not take me long to recover from a stressful event". Three of the items had to be reversed prior to summing and averaging scores. Within the sample, the reliability analysis of the BRS revealed a Cronbach's alpha of.840. The respondents scored an average on the BRS of 2.952 with a standard deviation of 0.755 . Scale summed scores can be grouped to classify resilience levels (65). BRS summed total scores between 1.00 and 2.99 are categorised as low resilience, 3.00-4.30 as normal resilience, and 4.31-5.00 as high resilience. Within the sample, $46,8 \%(N=1,160)$ could be classified as having low resilience, $49.7 \%(N=1,233)$ were classified as having normal resilience, and the remaining 3.5\% $(\mathrm{N}$ $=87$ ) had a high level of resilience. Using these group norms, the average resilience level of the final sample could be classified as "low".

\section{HE Support}

Definitions of resilience include resilient behaviours through the identification and utilisation of supportive resources (59). The C19 ISWS item assessing students' identification and satisfaction with support facilities; "There are sufficient support facilities within the HE institute (e.g., student counselling, online support)" was included in the model. Responses were required on a 5-point Likert scale. Scores were transformed so that higher scores indicated higher perceived availability of supporting facilities within the HE setting. For the sample, $27.6 \%$ indicated strong disagreement, or disagreement with the statement $(N=156, N=528$, respectively), whereas $26,5 \%$ either agreed or strongly agreed ( $N=595, N=61$, respectively). The remainder of the sample maintained a neutral attitude towards the availability of sufficient support facilities at the HE institute $(N=1,140)$.

\section{Statistical Analysis}

IBM SPSS Statistics for Windows, Version 27.0 was used to carry out statistical analyses. The extension Macro PROCESS (67) version 3.5 was used to test model fit regarding a serial mediation effect by resilience and HE support on academic stress and depression. To estimate power probabilities for the subgroups examined for model estimation differences, $G^{*}$ Power software version 3.1.9.6 was used (68).

The serial mediation analysis was run with Macro PROCESS to estimate effect sizes and model fit for five groups: (1) all HE students, (2) students who report experiencing low levels of academic stress during the Covid-19 pandemic, (3) students who report high levels of academic stress during the Covid19 pandemic, (4) students with CES-D8 scores indicating the presence of depression, and (5) students whose CES-D8 scale mean indicated the absence of depression.

During each group analysis, the nature of the relationship between X and Y (X: academic stress and Y: depression levels) was assessed directly, in addition to testing the indirect effect resulting from the two mediators resilience (M1) and HE support (M2), and their indirect serial mediation effect (Figure 1). The analytical workflow was based on previous work by Preacher and Hayes (69) where multiple mediation analysis is based on two elements. First, an examination is made to conclude whether the set of mediators transmits the effect of X to $\mathrm{Y}$, and second, the specific indirect effect associated with each presumed mediator is tested. Within this framework, total indirect effects 
need not be significant for identification of relevant specific indirect effects.

Total, direct, indirect, and partial effects included in the model were described as statistically significant if the corresponding 95\% confidence interval of the unstandardised effect size coefficient $b$ did not contain zero. If the direct path between $\mathrm{X}$ and $\mathrm{Y}\left(\mathrm{c}^{\prime}\right)$ was significant, and all three indirect pathways (a1 x b1; a2 x b2; and a1 $\mathrm{x}$ d $\mathrm{x}$ b2) yielded significant results, a partial serial mediation model is present. If the $c^{\prime}$ path effect between $\mathrm{X}$ and $\mathrm{Y}$ is non-significant and the three indirect pathways were significant, a full serial mediation model is present. If any of the indirect pathways fail to reach significance, the remaining indirect pathways were examined to assess the model.

During the Macro PROCESS analyses, bootstrap resampling value was set at 5,000. Each of the pathways was tested by regressing the corresponding variables. If the $b$ coefficient of the estimated direct, serial indirect, or independent indirect effects occurred within a $95 \%$ confidence interval range excluding zero, the null hypothesis of no significant predictive effect was rejected.

No missing data was present for the sample as only completed surveys were included. More so, due to the Likert-scale response methods employed to measure all included variables within the hypothesised model, no outliers were identified. The final dataset $(N=2,480)$ was screened for violations that would prevent accurate use of Macro PROCESS. Although normality testing revealed non-normal data (Shapiro-Wilk statistic $=0.76, p<$ 0.001), bootstrapping techniques used in PROCESS are robust against violations of normality by using confidence intervals to assess effect significance $(69,70)$. Post-hoc examination of power revealed that groups had sufficient detection power. All HE students, high academic stress students, and non-depressed students maintained a power coefficient of 1.000. A power coefficient of 0.999 was found for low academic stress students, and the power coefficient was 0.971 for depressed students (68).

Assessments were run to determine the presence of covariates. A two-step approach was used to examine sociodemographic variables for linear effects on depression. First, based on literature $(3,5,35,38,71)$, age, gender, migration background ("where you born in the Netherlands, or outside of the Netherlands?"), and family educational background of students (first generation $\mathrm{HE}$ student, vs. not the first generation) were selected and tested for significant effects on depression. During the second step, tests were run to determine each sociodemographic variable's relation to the independent variables academic stress, resilience, and HE support (72). All sociodemographic variables significantly correlated to at least one of the independent variables. Therefore, none were selected as covariates (see Table A2).

C19 ISWS data collection dates collided with governmentinduced changes in Covid-19 lockdown restrictions in the Netherlands. The survey was completed from May 6th 2020 until May 18th 2020, with a mean completion date of May 9th 2020 and a standard deviation of 3 days. As the introduction of the first steps towards reopening were introduced on May 11th, the dataset was inspected to cheque for date dependent effects on depression or academic stress ratings. Statistical analysis yielded no significant results ( $p=0.089$ and $p=0.194$, respectively).
TABLE 2 | Descriptive statistics and Pearson's correlation for all students on academic stress, depression, resilience, and HE support measures $(N=2,480)$.

\begin{tabular}{llcccccc}
\hline & M & SD & $\mathbf{1}$ & $\mathbf{2}$ & $\mathbf{3}$ & $\mathbf{4}$ \\
\hline 1. Academic Stress & 3.371 & 0.854 & $(-)$ & $0.404^{\star \star \star}$ & $-0.379^{\star \star \star}$ & $-0.282^{\star \star \star}$ \\
2. Depression & 2.280 & 0.619 &. & $(-)$ & $-0.238^{\star \star \star}$ & $-0.482^{\star \star \star}$ \\
3. & HE Support & 2.950 & 0.895 &. &. & $(-)$ & $0.149^{\star \star \star}$ \\
4. & Resilience & 2.952 & 0.755 &. &. &. & $(-)$ \\
\hline
\end{tabular}

***significant at $p<0.001$.

\section{RESULTS}

\section{All Students}

For all students, the total predictive effect of the model was 0.293 (see Tables 2, 4, Figure 2A). $64.85 \%$ of the effect originated in a direct effect between perceived academic stress and depressive symptoms, where higher levels of perceived academic stress significantly predict higher levels of depressive symptoms. Of the indirect effects, the strongest predictive effect is related to the pathway between academic stress and depression via resilience (at $78.64 \%$ of the indirect effects, effect size 0.081 ). The results confirm a serial mediation model for all $\mathrm{HE}$ students in predicting depressive symptoms from academic stress, resilience, and HE support. As the corresponding coefficients demonstrate contrasting directions, the analysis points towards a suppressive role of both resilience and HE support, as was proposed in the model hypothesis. As such, a 10\% rise in perceived academic stress is linked to a $4.08-5.40 \%$ increase in depression symptom severity, but, through partial mediation of resilience and HE support, the former effect is suppressed by $2.13-3.03 \% . \mathrm{R}^{2}$ indicates that the model predicts $32 \%$ of the variance, which is an adequate and substantial model fit $(73,74)$.

\section{Low Academic Stress Students}

When estimating the model effects for students who perceive low levels of academic stress, the total predictive effect of the model was not significant $(p=0.108)$. The result revealed just two significant partial effects (see Tables 3, 4, Figure 2B). The first includes a predictive effect of resilience on depression symptoms, with a coefficient of -0.281 . For every unit increase in resilience, student depression symptoms were predicted to decrease $2.55-11.50 \%$. The partial predictive effect of resilience on identification of HE support was significant at a threshold of 0.05 , with a coefficient of 0.305 . This finding suggests that higher resilience also predicts a higher capacity to identify $\mathrm{HE}$ support facilities.

\section{High Academic Stress Students}

The model effects for students who perceive high levels of academic stress, displayed a total predictive effect of. 424 between perceived academic stress and depression (see Tables 3, 4, Figure 2C). For every unit increase in academic stress, depression levels rise $5.64-11.30 \%$. Of this effect, $72.64 \%$ was related to the direct effect between academic stress and depression, with the remainder predominantly caused by the indirect effect via 

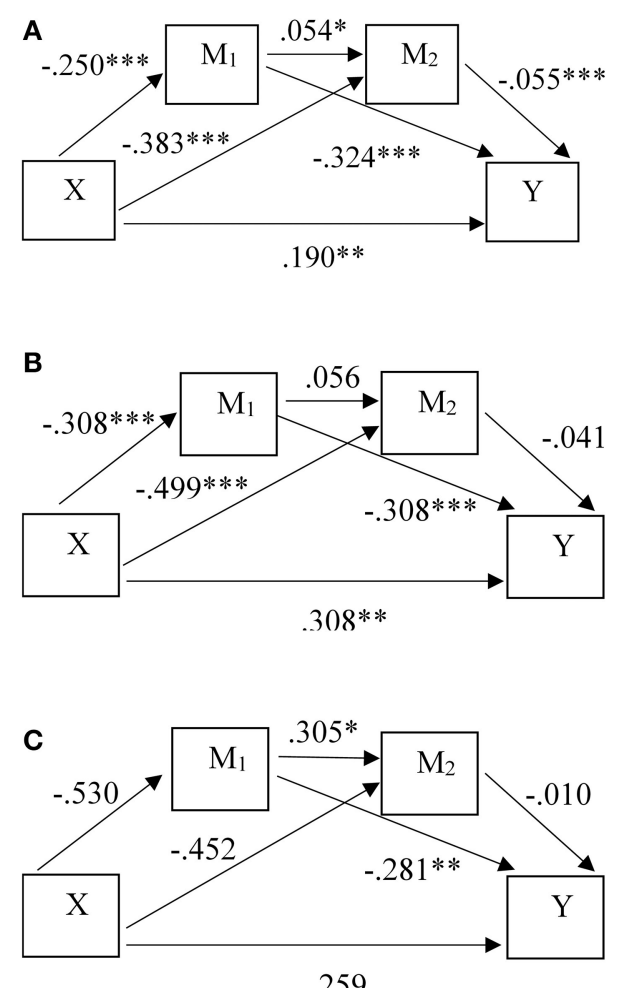

.259
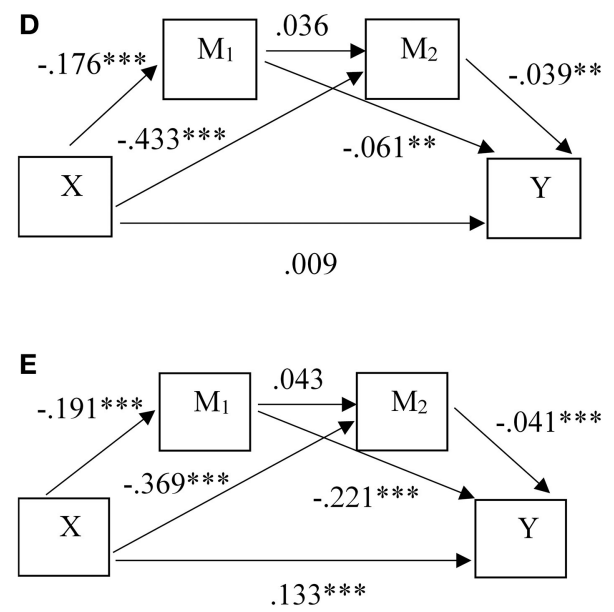

FIGURE 2 | Predictive model effects for the HE student groups: (A) all students $(N=2,480)$, (B) low academic stress students $(N=63)$, (C) high academic stress students ( $N=839)$, (D) depressed students $(N=404)$, (E) non-depressed students $(N=2,076)$. *significant at $p<0.05$, ${ }^{* *}$ significant at $p$ $<0.01,{ }^{\star \star \star}$ significant at $\mathrm{p}<0.001$.

resilience. The protective effect of resilience predicts a $0.98-$ $3.85 \%$ decrease in depressive symptoms. The predictive effect of resilience on HE support identification, and the predictive effect of HE support on depression remained insignificant. Results do not support a serial mediation model, but instead propose a single partial mediation model, where resilience partially mediates the relationship between academic stress and depression by acting
TABLE 3 | Descriptive statistics of the student subgroups on academic stress, depression, resilience, and HE support measures.

M

SD

Low academic stress $(N=63)$

Academic stress

1.480

0.289

Depression

1.762

0.568

HE Support

3.670

0.823

Resilience

3.476

0.794

High academic stress ( $N=839$ )

Academic stress

$\begin{array}{ll}4.611 & 0.283\end{array}$

Depression

2.557

0.602

HE Support

2.570

0.890

Resilience

2.708

0.746

Depressed $(N=404)$

Academic stress

4.209

0.701

Depression

3.277

0.264

HE Support

2.660

0.953

Resilience

2.400

0.710

Non-depressed ( $N=2,076$ )

Academic stress

3.619

0.848

Depression

2.085

HE support

3.010

0.461

Resilience

3.059

0.872

0.716

as a suppressor. For the entire model, $\mathrm{R}^{2}$ is 0.19 , which may be interpretated as an adequate and moderate model fit $(73,74)$.

\section{Depressed Students}

Result from the model analysis for depressed students, yielded a low total predictive effect, with an effect size of 0.037 (see Tables 3, 4, Figure 2D). In addition, the model explained $5.41 \%$ of the variance present in the sample, thus demonstrating a lack of model fit for depressed students. Of the pathways tested to estimate serial mediation effects between academic stress and depression, results indicated no significant direct effect between academic stress and depression, and an insignificant serial effect between resilience and HE support identification. As such, results support complete mediation effects of both resilience and HE support, which implies a parallel mediation model.

The predictive effect of perceived academic stress on depression was predominantly mediated by HE support $(60.71 \%$ of the indirect effect). However, effect sizes were small. A unit increase in resilience predicts a decrease in depressive symptoms of 0.63 - or $2.43 \%$, and a unit increase in HE support identification predicts a decrease in depression of $0.28-1.68 \%$. In practise, the total effects of these mediating pathways predict a drop in mean depression scores ranging between 3.268 and 3.239. Scores thus remain within the range indicating presence of depression (61).

\section{Non-depressed Students}

The total predictive effect of the model to assess depression levels in non-depressed HE students was 0.190, with a direct effect size of 0.133 (see Tables 3, 4, Figure 2E). This result indicates that 
TABLE 4 | Regression coefficients and significance tests for the explanatory model pathways between the five student groups.

\begin{tabular}{|c|c|c|c|c|c|}
\hline Pathway & b & $\mathbf{t}$ & $\mathbf{p}$ & $\mathbf{R}$ & $95 \% \mathrm{Cl}$ \\
\hline All students & & & & 0.32 & \\
\hline $\mathrm{a} 1$ & -0.250 & -14.642 & $<0.001^{* * *}$ & & -0.283 to -0.216 \\
\hline b1 & -0.324 & -22.823 & $<0.001^{* \star *}$ & & -0.352 to -0.297 \\
\hline b2 & -0.055 & -4.431 & $<0.001^{* * *}$ & & -0.080 to -0.031 \\
\hline$X$ on $Y$ & Effect & se & $\mathbf{t}$ & p & $95 \% \mathrm{Cl}$ \\
\hline Total & 0.293 & 0.013 & 21.961 & $<0.001^{\star \star \star}$ & 0.266 to 0.319 \\
\hline Ind. total & 0.103 & 0.009 & & & 0.085 to 0.121 \\
\hline Ind1 (a1 x b1) & 0.081 & 0.007 & & & 0.069 to 0.095 \\
\hline Ind2 (a2 x b2) & 0.021 & 0.005 & & & 0.011 to 0.032 \\
\hline a1 & -0.530 & -1.534 & 0.130 & & -1.222 to 0.169 \\
\hline a2 & -0.452 & 1.290 & 0.202 & & -1.152 to 0.249 \\
\hline b1 & -0.281 & 3.144 & $0.003^{*+* t}$ & & -0.460 to -0.102 \\
\hline b2 & 0.010 & 0.110 & 0.913 & & -0.164 to 0.183 \\
\hline$d$ & 0.305 & 2.399 & $0.020^{*}$ & & 0.051 to 0.560 \\
\hline$c^{\prime}$ & 0.259 & 1.086 & 0.282 & & -0.218 to 0.736 \\
\hline$X$ on $Y$ & Effect & se & $\mathbf{t}$ & $\mathrm{p}$ & $95 \% \mathrm{Cl}$ \\
\hline Total & 0.402 & 0.247 & 1.632 & 0.108 & -0.091 to 0.896 \\
\hline Ind. total & 0.143 & 0.119 & & & -0.070 to 0.398 \\
\hline Ind1 (a1 x b1) & 0.149 & 0.105 & & & -0.058 to 0.363 \\
\hline Ind2 (a2 x b2) & -0.004 & 0.049 & & & -0.094 to 0.115 \\
\hline d & 0.056 & 1.378 & 0.169 & & -0.024 to 0.137 \\
\hline$c^{\prime}$ & 0.308 & 4.543 & $<0.001^{\star \star \star *}$ & & 0.175 to 0.441 \\
\hline$X$ on $Y$ & Effect & se & $\mathbf{t}$ & p & $95 \% \mathrm{Cl}$ \\
\hline Total & 0.424 & 0.072 & 5.872 & $<0.001^{\star \star \star *}$ & 0.282 to 0.565 \\
\hline Ind. total & 0.116 & 0.033 & & & 0.055 to 0.183 \\
\hline Ind1 (a1 x b1) & 0.095 & 0.029 & & & 0.039 to 0.154 \\
\hline Ind2 (a2 x b2) & 0.020 & 0.012 & & & -0.001 to 0.048 \\
\hline \multirow[t]{2}{*}{ Ind3 (a1 x d x b2) } & 0.0007 & 0.001 & & & -0.0003 to 0.0027 \\
\hline & b & $t$ & $\mathrm{p}$ & $\mathbf{R}$ & $95 \% \mathrm{Cl}$ \\
\hline Depressed & & & & 0.05 & \\
\hline a1 & -0.176 & -3.531 & $<0.001^{* * t *}$ & & -0.274 to -0.078 \\
\hline a2 & -0.433 & -6.640 & $<0.001^{\star \star *}$ & & -0.561 to -0.305 \\
\hline b1 & -0.061 & -3.302 & $0.001^{* *}$ & & -0.097 to -0.025 \\
\hline b2 & -0.039 & -2.712 & $0.007^{* *}$ & & -0.067 to -0.011 \\
\hline$d$ & 0.036 & 0.557 & 0.578 & & -0.091 to 0.162 \\
\hline$c^{\prime}$ & 0.009 & 0.482 & 0.630 & & -0.029 to 0.048 \\
\hline$X$ on $Y$ & Effect & se & $\mathbf{t}$ & p & $95 \% \mathrm{Cl}$ \\
\hline Total & 0.037 & 0.019 & 1.980 & $0.048^{*}$ & 0.0003 to 0.0739 \\
\hline
\end{tabular}


TABLE 4 | Continued

\begin{tabular}{|c|c|c|c|c|c|}
\hline Pathway & b & $\mathbf{t}$ & p & $\mathbf{R}$ & $95 \% \mathrm{Cl}$ \\
\hline Ind. total & 0.028 & 0.009 & & & 0.011 to 0.046 \\
\hline Ind1 (a1 x b1) & 0.011 & 0.005 & & & 0.003 to 0.022 \\
\hline Ind2 (a2 x b2) & 0.017 & 0.008 & & & 0.003 to 0.033 \\
\hline \multirow[t]{2}{*}{ Ind3 (a1 x d x b2) } & 0.0002 & 0.001 & & & -0.0008 to 0.0015 \\
\hline & b & $t$ & $\mathbf{p}$ & $\mathbf{R}$ & $95 \% \mathrm{Cl}$ \\
\hline a2 & -0.369 & -17.091 & $<0.001^{* \star \star}$ & & -0.411 to -0.326 \\
\hline b1 & -0.221 & -17.456 & $<0.001^{* \star \star}$ & & -0.246 to -0.196 \\
\hline b2 & -0.041 & -3.730 & $<0.001^{* * *}$ & & -0.062 to -0.019 \\
\hline$d$ & 0.043 & 1.675 & 0.094 & & -0.007 to 0.093 \\
\hline$c^{\prime}$ & 0.133 & 11.618 & $<0.001^{* * *}$ & & 0.110 to 0.155 \\
\hline Ind1 (a1 x b1) & 0.042 & 0.005 & & & 0.033 to 0.052 \\
\hline Ind2 (a2 x b2) & 0.015 & 0.004 & & & 0.007 to 0.023 \\
\hline Ind3 (a1 x d x b2) & 0.0003 & 0.0002 & & & -0.0001 to 0.0008 \\
\hline
\end{tabular}

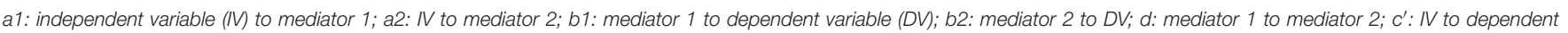
variable. *significant at $p<0.05$; ${ }^{\star \star \star}$ significant at $p<0.001$.

$70.00 \%$ of the model's predictive effect originates from the direct predictive effect of academic stress on depressive symptoms. Both an indirect predictive effect via resilience and HE support proved significant, but the serial mediating pathway did not yield a significant result (effect size 95\% Confidence Interval (CI) = $-0.0001,-0.0008)$. The indirect effect was predominantly driven by the pathway of resilience mediation, at $72.41 \%$ of the total indirect effect. Results support independent partial mediating effects of resilience and HE support, where they act as suppressors of the relationship between academic stress and depression in parallel mediation. The largest effect originates from a direct predictive effect of academic stress on depression, at an estimated effect size of 0.133 . A unit increase in perceived academic stress predicts an increase in depressive symptoms of $2.75-3.88 \%$. Indirect effects collectively decrease depressive symptoms $1.13-$ $1.78 \%$.

\section{DISCUSSION}

The current study examined the relationships between Covid19 related academic stress and depression with mediation effects of resilience and HE support, among students studying at higher education institutes during the corona crisis in the Netherlands. For all student subgroups, predictive suppressive effects of resilience on depression rates were demonstrated. More so, students subgroups experiencing low academic stress, and those experiencing depression, cease to demonstrate a direct effect of academic stress on predicted depression levels, whereas this direct effect is found for other student groups. In addition, a protective predictive effect through identification of HE support was significant for the entire student sample, as well as for subgroups of depressed, and non-depressed students, but not for low and high academic stress groups. Furthermore, serial mediation was demonstrated for all $\mathrm{HE}$ students in general, but it ceased to exist in subgroups. The study of these dynamics provides relevant insights as subgroup examinations were conducted based on research recommendations $(16,18)$. By comparing student groups based on levels of stress and depression, significant nuances and differences appear which give direction to strategies for student wellbeing enhancement at HE institutes.

In keeping with other studies on student wellbeing, the current study demonstrates a significant relationship between academic stress and depression among students $(18,75)$. When analysing the total sample, both resilience and HE support mediate the effect of academic stress on development of depressive symptoms for HE students, including a serial mediation between resilience and HE support.

A similar model is presented for non-depressed HE students, where approximately one third of the effect of academic stress on depression is mediated though resilience and HE support, though this group lacked serial mediation. Our findings support previous demonstrations of a protective mediating role for resilience and identification of support resources in the development of psychological problems among students $(5,28,52)$, and provides corroboration for a link between resilience and the ability to identify helpful resources in the environment for students generally $(59,60)$.

For HE students experiencing low academic stress, higher resilience predicts lower depression scores, in addition to predicting higher identification of $\mathrm{HE}$ support resources. In contrast to other groups, students who experience low academic 
stress demonstrate no direct or indirect effect of academic stress on wellbeing due to the educational transition. A plausible explanation for this finding regards the higher resilience levels present among this subgroup, as higher resilience promotes higher levels of adaptive behaviours, in turn reducing negative impacts from perceived stress (58). More so, this subgroup may perceive the Covid-19 related educational transition as nonthreatening, which also serves to protect against negative stress effects on student wellbeing (19).

When students do perceive high levels of academic stress during the Covid-19 crisis, the strongest predictive effect originates from a direct effect of academic stress on depression, and a predictive effect of resilience was found with the greatest indirect mediation. In contrast to the entire sample and depressed or non-depressed subgroups, the protective effect of HE support is lost for students with high levels of academic stress. This loss suggests a stress-induced impairment in students' ability to identify support facilities, which is supported by research describing inhibited adaptive behaviours if one's stress response becomes overwhelmed (54, 58). Akin to most student groups, students burdened by high academic stress stand to profit from resilience enhancement strategies and could benefit from programs focussed on the remediation of academic stress perception following the educational transition to online teaching.

As for HE students who experience depression, different outcomes emerge. Among depressed students, a relatively stronger mediation through HE support is found compared to the mediating effect of resilience. This finding indicates that the protective effects for this group are driven predominantly by the ability to identify HE support resources. Results may indicate that depressed students are turning to HE institutes in their search for support resources but remain unaware of their presence or are unsuccessful in locating available support facilities. Alternatively, students enduring psychological problems may experience helpseeking barriers, including the perception that no one will be able to offer the support that they need, which may negatively influence their ability to identify useful resources $(24,25)$. These students thus stand to benefit from promotion of comprehensive support facilities, a suggestion which has also been made in other studies on student wellbeing during the Covid-19 pandemic (43).

The lack of a strong protective mediation from resilience among depressed students reiterates previous work describing insufficient levels of resilience when psychopathology sets in $(54,58)$. The current findings suggest that depressed students require a different approach when forming strategies to increase wellbeing. This topic thus requires further attention in future research. For depressed students, the current explanatory model explains little variance, suggesting alternative pathways by which depression would be better predicted. With research demonstrating that $75 \%$ of people experiencing depression will have an onset before 24 years of age (11), it seems plausible that the depression rates captured regard recurrence or persistence and are thus not predicted by academic stress caused by the educational transition following the pandemic.

Instead, researchers propose that personality traits, comorbidity, or risk factors relating to hopelessness, and problem-solving capacity are all predictive of depression development $(12,75,76)$. The supporting role of educational institutes in facilitating support for this burdened group of students should thus be subject of further investigation, especially given evidence that increased psychological distress is implicated in academic failure and study discontinuation $(7,8,18)$.

\section{Limitations}

Although the current study furthers understanding of the relationship between academic stress, resilience, and HE support on depressive symptoms for HE students during the Covid19 pandemic in the Netherlands, there are some limitations. First, the sample contained an overrepresentation of female students. Although higher response rates from female students are often present within examinations of student populations (77), replications with balanced gender groups may provide added insight or nuances. Second, the cross-sectional nature of the current study would be enriched by examining student groups within a longitudinal design, where repeated measures study could examine the temporal persistence of Covid-19 related impacts on wellbeing. Third, with little variation captured for depressed HE students, this group should receive independent focus to identify relevant explanatory pathways, as well as to reveal potential avenues for HE support and intervention. Fourth, this study assessed academic stress via four relevant stressors, although additional sources of academic stress are found among students, including time constraints, parental pressures, teachers' expectations, and self-perceptions $(78,79)$. As such, further study including additional sources of academic stress will serve to improve understanding of the collective and independent effects of academic stressors on student wellbeing. Finally, with resilience scores generally within the lower range in the current student sample, additional study of resilience among HE students will expand collective knowledge and serve to further inform enhancement strategies.

\section{Practical Implications and Future Directions}

According to our findings, the greatest overall improvements to HE student wellbeing during the Covid-19 pandemic can be attained by promoting resilience in addition to decreasing perceived Covid-19 related academic stress for specific subgroups. Higher educational institutes should focus on student perceptions of academic workload, expectations, and anticipated study delays, and how to remedy stress elevations which hamper psychological wellbeing through resilient response. More so, expanding perceived academic stress measures will aid research on students' academic stress experiences beyond the confines of the pandemic, as research demonstrates that students also experience academic stressors in non-pandemic academic settings $(7,78)$. Furthermore, an exploration of means with which to increase resilience should yield fruitful wellbeing enhancement strategies. The Covid-19 related restrictions that preclude live contact, need not act as a barrier for proactive development of tools that promote resilience 
among students during this time, as online and informal resources can also offer benefits to wellbeing $(24,25,47,48)$.

With studies proposing that informal support is generally preferred by young adults due to financial considerations, higher availability, and lower associations with stigmatisation (25), their applicability within the currents predictive models deserves further scrutiny. Moreover, research indicates that facilitators of help-seeking among students include increased education and awareness, encouragement, removal of treatment scepticism, and the provision of accessible resources such as student counselling $(23,24,27)$. As such, HE institutes could stimulate student wellbeing by exploring relevant facilitators of student support seeking, in addition to scrutinising HE support service accessibility and availability.

The current findings also argue for a differential research approach when examining wellbeing of HE students who are experiencing depression. These students may not receive any notable benefit from perceived academic stress reduction or resilience enhancement, and as such require further research to identify relevant predictors and effective interventions. It may also be the case that this group requires support services that are not typically available via HE institutes, or that a lack of academic attendance resulting from psychological distress keeps these students outside of the range of HE support services. Given their difficult disposition, understanding wellbeing dynamics of depressed students warrants continued exploration.

The current study offers HE institutes in the Netherlands enriched understanding on how to best support student wellbeing throughout the remainder of the Covid-19 pandemic, based on group levels of academic stress and depressive symptoms, which had not been investigated previously. If future circumstances demand student isolation, students may continually be required to conduct studies via an online educational environment for extensive periods of time. Under such circumstances, mitigation of perceived academic stress and enhancement of resilience offer protective means with which to positively promote student wellbeing.

\section{CONCLUSIONS}

For HE students studying in the Netherlands, model testing demonstrates that perceived academic stress positively predicts depressive symptoms during the coronavirus pandemic and its implications for online education. Moreover, within the model test for the entire student sample, protective serial mediation is present via resilience, and HE support. Subgroup examinations demonstrated parallel mediation, partial predictive effects, in addition to a lack of model fit for specific subgroups of students. These findings suggest that HE institutes may increase student

\section{REFERENCES}

1. Hartley MT. Examining the Relationships Between Resilience, Mental Health, and Academic Persistence in Undergraduate College Students. J Am Coll Health. (2011) 59:596-604. doi: 10.1080/07448481.2010.515632 wellbeing generally by enhancing resilience and HE support, as well as by decreasing perceived academic stress. However, specific approaches could be required if the aim concerns enhancement of student wellbeing among student subgroups. Wellbeing enhancement among students during of the Covid-19 pandemic should be strategically reviewed by HE institutes and should include focus on support service availability, visibility, and range of services.

\section{DATA AVAILABILITY STATEMENT}

The datasets presented in this article are not readily available because participants of this study did not consent to public availability of their data. Upon request from collaborating researchers within the C19 ISWS consortium, data is available as relevant consent was provided by participants. Requests to access the datasets should be directed to Rutger Kappe, rutger.kappe@inholland.nl.

\section{ETHICS STATEMENT}

The studies involving human participants were reviewed and approved by Ethics Committee for Social Sciences and Humanities at the University of Antwerp and the Institutional Review Board InHolland University of Applied Sciences. Written informed consent for participation was not required for this study in accordance with the national legislation and the institutional requirements.

\section{AUTHOR CONTRIBUTIONS}

RK aided in survey design, survey distribution, and contribution of materials. MV analyzed the data and wrote the manuscript. RK and MV conducted literature research. Both authors contributed to the article and approved the submitted version.

\section{FUNDING}

This work was supported by the department of Student Success, InHolland University of Applied Sciences, Haarlem, the Netherlands.

\section{ACKNOWLEDGMENTS}

We would like to thank all higher education students who participated in this study on wellbeing during the corona crisis. We also thank Lieke Woelders, Mascha Enthoven, Sanne van Herpen, and Lisa Klinkenberg for their critical insight and detailed feedback throughout the development of this study. Sources of stress and their associations with mental disorders among college students: Results of the world health organization world mental health surveys international college student initiative. Front. Psychol. (2020) 111. doi: 10.3389/fpsyg.2020.01759 
3. McLafferty M, Lapsley CR, Ennis E, Armour C, Murphy S, Bunting BP, et al. Mental health, behavioural problems and treatment seeking among students commencing university in northern Ireland. PLoS ONE. (2017) 12:e0188785. doi: 10.1371/journal.pone.0188785

4. Wörfel F, Gusy B, Lohmann K, Töpritz K, Kleiber D. Mental health problems among university students and the impact of structural conditions. J Public Health. (2016) 24:125-33. doi: 10.1007/s10389-015-0703-6

5. Zhang X, Huang P, Li B, Xu W, Li W, Zhou B. The influence of interpersonal relationships on school adaptation among Chinese university students during COVID-19 control period: Multiple mediating roles of social support and resilience. J Affect Disord. (2021) 285:97-104. doi: 10.1016/j.jad.2021.02.040

6. Tosevski DL, Milovancevic MP, Gajic SD. Personality and psychopathology of university students. Curr Opin Psychiatry. (2010) 23:48-52. doi: 10.1097/YCO.0b013e328333d625

7. Dopmeijer J. Running on empty: The impact of challenging student life on wellbeing and academic performance. Amsterdam: Universiteit van Amsterdam. (2021).

8. Svanum S, Zody ZB. Psychopathology and college grades. J Couns Psychol. (2001) 48:72-6. doi: 10.1037/0022-0167.48.1.72

9. Centraal Bureau voor de Statistiek. Data from: Welzijn: Kerncijfers, persoonskenmerken (2021). Available online at: https://opendata.cbs.nl/\#/ CBS/nl/dataset/82634NED/table?searchKeywords=depressie\%20Hbo

10. De Graaf R, Ten Have M, Van Gool C,Van Dorsselaer S. Prevalence of mental disorders and trends from 1996 to 2009. Results from the Netherlands Mental Health Survey and Incidence Study-2. Soc. Psychiatry. Psychiatr. Epidemiol. (2012) 47(2):203-13. doi: 10.1007/s00127-0100334-8

11. Kessler RC, Berglund P, Demler O, Jin R, Merikangas KR, Walters EE. Lifetime prevalence and age-of-onset distributions of DSM-IV disorders in the national comorbidity survey replication. Arch Gen Psychiatry. (2005) 62:593-602. doi: 10.1001/archpsyc.62.6.593

12. Rohde P, Lewinsohn PM, Klein DN, Seeley JR, Gau JM. Key characteristics of major depressive disorder occurring in childhood, adolescence, emerging adulthood, and adulthood. Clin Psychol Sci. (2013) 1:41-53. doi: 10.1177/2167702612457599

13. Centraal Bureau voor de Statistiek. Data from: Hoger beroepsonderwijs. Onderwijsinstellingen; grootte, soort, levensbeschouwelijke grondslag. (2005) Available online at: https://www.cbs.nl/nl-nl/cijfers/detail/03753?dl=3D073

14. Ibrahim AK, Kelly SJ, Adams CE, Glazebrook C, A. systematic review of studies of depression prevalence in university students. J Psychiatr Res. (2013) 47:391-400. doi: 10.1016/j.jpsychires.2012.11.015

15. He FX, Turnbull B, Kirshbaum MN, Phillips B, Klainin-Yobas P. Assessing stress, protective factors and psychological well-being among undergraduate nursing students. Nurse Educ Today. (2018) 68:4-12. doi: 10.1016/j.nedt.2018.05.013

16. Robotham D. Stress among higher education students: Towards a research agenda. High Educ. (2008) 56:735-46. doi: 10.1007/s10734-008-9137-1

17. Saxena S, Mani R, Dwivedi A, Ryali V, Timothy A. Association of educational stress with depression, anxiety, and substance use among medical and engineering undergraduates in India. Ind Psychiatry J. (2019) 28:1609. doi: 10.4103/ipj.ipj_3_20

18. Newcomb-Anjo SE, Villemaire-Krajden R, Takefman K, Barker ET. The unique associations of academic experiences with depressive symptoms in emerging adulthood. Emerg Adulthood. (2017) 5:75-80. doi: 10.1177/2167696816657233

19. Haldorsen H, Bak NH, Dissing A, Petersson B. Stress and symptoms of depression among medical students at the university of Copenhagen. Scand J Public Health. (2014) 42:89-95. doi: 10.1177/1403494813503055

20. Rosenstock IM. Why people use health services. The Milbank Memorial Fund Quarterly. (1966) 44:94-127. doi: 10.2307/3348967

21. Awoke M, Mamo G, Abdu S, Terefe B. Perceived stress and coping strategies among undergraduate health science students of jimma university amid the COVID-19 outbreak: online cross-sectional survey. Front Psychol. (2021) 12:639955. doi: 10.3389/fpsyg.2021.639955

22. Rusch A, Rodriguez-Quintana N, Choi SY, Lane A, Smith M, Koschmann E, et al. School professional needs to support student mental health during the COVID-19 pandemic. Front Educ. (2021) 6:663871. doi: 10.3389/feduc.2021.663871
23. Baik C, Larcombe W, Brooker A. How universities can enhance student mental wellbeing: the student perspective. High. Educ. Res. Dev. (2019):1469. doi: 10.1080/07294360.2019.1576596

24. Gulliver A, Griffiths KM, Christensen H. Perceived barriers and facilitators to mental health help-seeking in young people: A systematic review. BMC Psychiatry. (2010) 10:113. doi: 10.1186/1471-244X-10-113

25. Ryan ML, Shochet IM, Stallman HM. Universal online interventions might engage psychologically distressed university students who are unlikely to seek formal help. Adv Ment Health. (2010) 9:73-83. doi: 10.5172/jamh.9.1.73

26. Raffaelli M, Andrade FCD, Wiley AR, Sanchez-Armass O, Edwards LL, Aradillas-Garcia C. Stress, social support, and depression: A test of the stressbuffering hypothesis in a Mexican sample. J Res Asolesc. (2013) 23:2839. doi: 10.1111/jora.12006

27. Eisenberg D, Golberstein E, Gollust SE. Help-Seeking and Access to Mental Health Care in a University Student Population. Med Care. (2007) 45:594601. doi: 10.1097/MLR.0b013e31803bb4c1

28. Tasso AF, Hisli Sahin N, San Roman GJ. COVID-19 disruption on college students: Academic and socioemotional implications. Psychol Trauma: Theory Res Pract Policy. (2021) 13:9-15. doi: 10.1037/tra0000996

29. Van de Velde S, Buffel V, Bracke P, Van Hal G, Somogyi NM, Willems B, et al. The COVID-19 international student well-being study. Scand J Public Health. (2021) 49:114-22. doi: 10.1177/1403494820981186

30. Zapata-Garibay R, González-Fagoaga JE, Meza-Rodríguez EB, SalazarRamírez E, Plascencia-López I, González-Fagoaga CJ. Mexico's higher education students' experience during the lockdown due to the COVID-19 pandemic. Front Educ. (2021) 6:683222. doi: 10.3389/feduc.2021.683222

31. Kappe FR, Knuiman C, Woelders CS. Student life in time of corona (2020). Haarlem: Hogeschool InHolland. Available online at: https://hbo-kennisbank. nl/details/sharekit_inholland:oai:surfsharekit.nl:2771f783-2c3a-48c2-ace0a227a6735d06\#

32. Bolumole M. Student life in the age of COVID-19. High Educ Res Dev. (2020) 39:1357-61. doi: 10.1080/07294360.2020.1825345

33. Brooks S, Webster R, Smith L, Woodland L, Wessely S, Greenberg N, et al. The psychological impact of quarantine and how to reduce it: rapid review of the evidence. Lancet. (2020) 395:912-20. doi: 10.1016/S0140-6736(20)30460-8

34. Green W, Anderson V, Tait K, Tran LT. Precarity, fear and hope: reflecting and imagining in higher education during a global pandemic. High Educ Res Dev. (2020) 39:1309-12. doi: 10.1080/07294360.2020.1826029

35. Ahmed MZ, Ahmed O, Aibao Z, Hanbin S, Siyu L, Ahmad A. Epidemic of COVID-19 in China and associated psychological problems. Asian J Psychiatr. (2020) 51:102092. doi: 10.1016/j.ajp.2020.102092

36. Balsamo M, Carlucci L. Italians on the age of COVID-19: The self-reported depressive symptoms through web-based survey. Front. Psychol. (2020) 11:569276. doi: 10.3389/fpsyg.2020.569276

37. Rabiee- Khan F, Biernat K. Student well-being during the first wave of COVID-19 pandemic in Birmingham, UK: Zenodo. (2021) p. 4572408.

38. Rossi R, Socci V, Talevi D, Mensi S, Niolu C, Pacitti F, et al. COVID19 pandemic and lockdown measures impact on mental health among the general population in Italy. Front Psychiatry. (2020) 11:790. doi: 10.3389/fpsyt.2020.00790

39. Stathopoulou T, Mouriki A, Papaliou O. Student Well-Being During the Covid-19 Pandemic in Greece. Results from the C19 ISWS Survey (Version 1) Zenodo. (2020).

40. Wang X, Hegde S, Son C, Keller B, Smith A, Sasangohar F. Investigating mental health of US college students during the COVID19 pandemic: Cross-sectional survey study. J Med Internet Res. (2020) 22:e22817. doi: $10.2196 / 22817$

41. Matos Fialho PM, Spatafora F, Kühne L, Busse H, Helmer SM, Zeeb H, et al. Perceptions of study conditions and depressive symptoms during the COVID-19 pandemic among university students in germany: results of the international COVID-19 student well-being study. Front Public Health. (2021) 9:674665. doi: 10.3389/fpubh.2021.674665

42. Tavolacci MP, Wouters E, Van de Velde S, Buffel V, Déchelotte P, Van Hal G, et al. The Impact of COVID-19 Lockdown on Health Behaviors among Students of a French University. Int J Environ Res Public Health. (2021) 18:4346. doi: 10.3390/ijerph18084346

43. Xu Y, Su S, Jiang Z, Guo S, Lu Q, Liu L, et al. Prevalence and risk factors of mental health symptoms and suicidal behavior among university students 
in wuhan, china during the COVID-19 pandemic. Front Psychiatry. (2021) 12:695017. doi: 10.3389/fpsyt.2021.695017

44. Zhang Y, Bao X, Yan J, Miao H, Guo C. Anxiety and depression in chinese students during the COVID-19 pandemic: a meta-analysis. Front Public Health. (2021) 9:697642. doi: 10.3389/fpubh.2021.697642

45. Hale T, Angrist N, Goldszmidt R, Kira K, Petherick A, Phillips T, et al. A global panel database of pandemic policies (Oxford COVID19 Government Response Tracker). Nat Hum Behav. (2021) 5:52938. doi: 10.1038/s41562-021-01079-8

46. Rijksinstituut voor Volksgezondheid en Milieu. Coronavirus Tijdlijn (2020). Available online at: https://www.rijksoverheid.nl/onderwerpen/coronavirustijdlijn

47. Davies EB, Morriss R, Glazebrook C. Computer-delivered and web-based interventions to improve depression, anxiety, and psychological well-being of university students: A systematic review and meta-analysis. J Med Internet Res. (2014) 16:e130. doi: 10.2196/jmir.3142

48. Farrer L, Gulliver A, Chan JKY, Batterham PJ, Reynolds J, Calear A, et al. Technology-based interventions for mental health in tertiary students: Systematic review. J Med Internet Res. (2013) 15:e101. doi: 10.2196/jmir.2639

49. Nguyen-Feng VN, Greer CS, Frazier P. Using online interventions to deliver college student mental health resources: Evidence from randomized clinical trials. Psychol Serv. (2017) 14:481-9. doi: 10.1037/ser0000154

50. Smith BW, Dalen J, Wiggins K, Tooley E, Christopher P, Bernard J. The brief resilience scale: Assessing the ability to bounce back. Int J Behav Med. (2008) 15:194-200. doi: 10.1080/10705500802222972

51. Leipold B, Munz M, Michéle-Malkowsky A. Coping and resilience in the transition to adulthood. Emerg Adulthood. (2019) 7:12-20. doi: 10.1177/2167696817752950

52. Hu T, Zhang D, Wang J, A. meta-analysis of the trait resilience and mental health. Pers Individ Differ. (2015) 76:18-27. doi: 10.1016/j.paid.2014.11.039

53. Luthar SS, Cicchetti D, Becker B. The construct of resilience: A critical evaluation and guidelines for future work. Child Dev. (2000) 71:54362. doi: 10.1111/1467-8624.00164

54. Richardson GE, Neiger B, Jensen S, Kumpfer K. The resiliency model. Health Educ J. (1990) 21:33-9. doi: 10.1080/00970050.1990.10614589

55. Vinkers CH, van Amelsvoort T, Bisson JI, Branchi I, Cryan JF, Domschke $\mathrm{K}$, et al. Stress resilience during the coronavirus pandemic. Eur Neuropsychopharmacol. (2020) 35:12-6. doi: 10.1016/j.euroneuro.2020.05.003

56. Veronese G, Mahamid F, Bdier D, Pancake R. Stress of COVID-19 and mental health outcomes in Palestine: The mediating role of well-being and resilience. Health Psychol Rep. (2021) 13. doi: 10.5114/hpr.2021.104490

57. Yalçin I, Can N, Mançe Çalişir Ö, Yalçin S, Çolak B. Latent profile analysis of COVID-19 fear, depression, anxiety, stress, mindfulness, and resilience. Curr Psychol. (2021) 1-11. doi: 10.1007/s12144-021-01667-x

58. Fergus S, Zimmerman MA. Adolescent resilience: A framework for understanding healthy development in the face of risk. Annu Rev Public Health. (2005) 6:399-419. doi: 10.1146/annurev.publhealth.26.021304. 144357

59. Enthoven MEM. The ability to bounce beyond: The contribution of the school environment to the resilience of Dutch middle-adolescents from a low SES background. Utrecht: Hogeschool Utrecht. (2007).

60. Rodriguez-Llanes JM, Vos F, Guha-Sapir D. Measuring psychological resilience to disasters: Are evidence-based indicators an achievable goal? J Environ Health. (2013) 12:115. doi: 10.1186/1476-069X12-115

61. Schane RE, Walter LC, Dinno A, Covinsky KE, Woodruff PG. Prevalence and risk factors for depressive symptoms in persons with chronic obstructive pulmonary disease. J Gen Intern Med. (2008) 23:175762. doi: 10.1007/s11606-008-0749-Z

62. Van de Velde S, Buffel V, Wouters E. Questionnaire of the COVID19 international student well-being study. Zenodo. (2020) 31. doi: 10.5281/zenedo.3928457

63. Van de Velde S, Levecque K, Bracke P. Measurement equivalence of the CESD 8 in the general population in Belgium: A gender perspective. Arch Belg Med Soc. (2009) 67:15-29. doi: 10.1186/0778-7367-67-1-15
64. Karim J, Rehman S, Bibi Z, Weisz R. Validation of the eight-item center for epidemiologic studies depression scale. Curr Psychol. (2015) 34:681. doi: 10.1007/s12144-014-9281-y

65. Andresen EM, Malmgren JA, Carter WB, Patrick DL. Screening for depression in well older adults: Evaluation of a short form of the CES-D. Am J Prev Med. (1994) 10:77-84. doi: 10.1016/S0749-3797(18)30622-6

66. Radloff LS. The CES-D Scale: A self-report depression scale for research in the general population. Appl Psychol Meas. (1977) 1:385-401. doi: 10.1177/014662167700100306

67. Hayes AF, Little TD. Introduction to mediation, moderation, and conditional process analysis: A regression-based approach ( $2^{\text {nd }}$ Ed.). New York: Guildford Press (2018) p. 692.

68. Faul F, Erdfelder E, Buchner A. Lang AG. Statistical power analyses using $\mathrm{G}^{*}$ Power 31: Tests for correlation and regression analyses. Behav Res Methods. (2009) 41:1149-60. doi: 10.3758/BRM.41.4.1149

69. Preacher KJ, Hayes AF. Asymptotic and resampling strategies for assessing and comparing indirect effects in multiple mediator models. Behav Res Methods. (2008) 40:879-91. doi: 10.3758/BRM.40.3.879

70. Fritz MS, MacKinnon DP. Required sample size to detect the mediated effect. Psychol Sci. (2007) 18:233-9. doi: 10.1111/j.1467-9280.2007.01882.x

71. Simegn W, Dagnew B, Yeshaw Y, Yitayih S, Woldegerima B, Dagne H. Depression, anxiety, stress and their associated factors among Ethiopian University students during an early stage of COVID-19 pandemic: An online-based cross-sectional survey. PLoS One. (2021) 16:e0251670. doi: 10.1371/journal.pone.0251670

72. Agresti A, Finlay B. Statistical Methods for the Social Sciences (4th edition). London: Pearson (2009) p. 624.

73. Cohen J. Statistical power analysis for the behavioral sciences (2nd Ed.). New York: Routledge. (1988) p. 579.

74. Falk RF, Miller NB. A primer for soft modelling ( $1^{\text {st }}$ Ed.). Ohio: University of Akron Press. (1992) p. 103.

75. Eremsoy CE, Çelimli S, Gençöz T. Students under academic stress in a Turkish university: Variables associated with symptoms of depression and anxiety. Curr Psychol. (2005) 24:123-33. doi: 10.1007/s12144-005-1011-z

76. Vinberg Christensen M, Vedel Kessing L. Do personality traits predict first onset in depressive and bipolar disorder? Nord J Psychiatry. (2006) 60:7988. doi: $10.1080 / 08039480600600300$

77. Porter SR, Whitcomb ME. Non-response in student surveys: The role of demographics, engagement and personality. Res High Educ. (2005) 46:12752. doi: 10.1007/s11162-004-1597-2

78. Bedewy D, Gabriel A. Examining perceptions of academic stress and its sources among university students: The perception of academic stress scale. Health Psychol Open. (2015). 2: 1-9. doi: 10.1177/20551029155 96714

79. França FDP, Dias TL. Validity and reliability of the perceptions of academic stress scale. Psicologia: Teoria e Prática. (2021) 23:1-21. doi: 10.5935/1980-6906/ePTPPA13041

Conflict of Interest: The authors declare that the research was conducted in the absence of any commercial or financial relationships that could be construed as a potential conflict of interest.

Publisher's Note: All claims expressed in this article are solely those of the authors and do not necessarily represent those of their affiliated organizations, or those of the publisher, the editors and the reviewers. Any product that may be evaluated in this article, or claim that may be made by its manufacturer, is not guaranteed or endorsed by the publisher.

Copyright $\odot 2021$ Versteeg and Kappe. This is an open-access article distributed under the terms of the Creative Commons Attribution License (CC BY). The use, distribution or reproduction in other forums is permitted, provided the original author(s) and the copyright owner(s) are credited and that the original publication in this journal is cited, in accordance with accepted academic practice. No use, distribution or reproduction is permitted which does not comply with these terms. 


\section{APPENDIX}

TABLE A1 | Government response stringency Index for the Netherlands with implementation dates of government-imposed restrictions.

\begin{tabular}{|c|c|c|}
\hline Date & $\begin{array}{l}\text { Government } \\
\text { response } \\
\text { stringency } \\
\text { index }\end{array}$ & Description \\
\hline February $27^{\text {th }}, 2020$ & 5.56 & $\begin{array}{l}\text { First national case of Covid-19 in } \\
\text { Tilburg (Northern Brabant). }\end{array}$ \\
\hline March $6^{\text {th }}, 2020$ & 11.11 & $\begin{array}{l}\text { First Covid- } 19 \text { related death and } \\
\text { subsequent first implementations of } \\
\text { covid- } 19 \text { related health advice for } \\
\text { Brabant province. }\end{array}$ \\
\hline March $13^{\text {th }}, 2020$ & 53.70 & $\begin{array}{l}\text { Introduction of flight restrictions from } \\
\text { high-risk countries, restriction on } \\
\text { group sizes in all public domains and } \\
\text { a ban on teaching at location for all } \\
\text { higher educational institutes }\end{array}$ \\
\hline March $23^{\text {rd }}, 2020$ & 78.70 & Start of the "Intelligent Lockdown". \\
\hline May $11^{\text {th }}, 2020$ & 71.30 & $\begin{array}{l}\text { First ease of government-imposed } \\
\text { restrictions, including the reopening of } \\
\text { public libraries, middle schools, and } \\
\text { some outdoor sport activities. }\end{array}$ \\
\hline
\end{tabular}

TABLE A2 | Covariate analysis.

\begin{tabular}{|c|c|c|c|c|c|}
\hline \multirow[t]{2}{*}{ Scale } & & \multicolumn{4}{|c|}{ Sociodemographic variables } \\
\hline & & Gender & Age & $\begin{array}{l}\text { Migration } \\
\text { status }\end{array}$ & $\begin{array}{c}\text { HE } \\
\text { Generation }\end{array}$ \\
\hline \multirow[t]{2}{*}{ Depression } & Pearson's $r$ & 0.074 & 0.101 & 0.081 & 0.045 \\
\hline & $p$-value & $<0.001^{\star \star \star}$ & $<0.001^{\star \star \star}$ & $<0.001^{\star \star \star}$ & $0.027^{\star}$ \\
\hline \multirow[t]{2}{*}{ Aca stress } & Pearson's $r$ & 0.009 & -0.012 & 0.007 & 0.068 \\
\hline & $p$-value & 0.664 & 0.550 & 0.721 & $0.001^{\star \star \star}$ \\
\hline \multirow[t]{2}{*}{ Resilience } & Pearson's $r$ & -0.159 & -0.041 & 0.015 & -0.041 \\
\hline & $p$-value & $<0.001^{\star \star \star}$ & $0.042^{*}$ & 0.466 & $0.043^{*}$ \\
\hline \multirow[t]{2}{*}{ HE Support } & Pearson's $r$ & 0.037 & -0.073 & -0.046 & -0.036 \\
\hline & $p$-value & 0.067 & $<0.001^{* \star *}$ & $0.023^{\star}$ & 0.072 \\
\hline
\end{tabular}

A significant independent direct effect on depression was taken as reason to include the sociodemographic variable as a covariate in the final analysis $(N=2,480)$. " significant at $p<0.05 ;{ }^{* * *}$ significant at $p<0.001$. 